\title{
Determinan Lama Rawat Inap Pasien Balita dengan Diare
}

\author{
Determinants of Length of Stay Children Under 5 with Diarrhea
}

\author{
Endang Poerwati \\ Rumah Sakit Umum Daerah Pasar Rebo Jakarta
}

\begin{abstract}
ABSTRAK
Gastroenteritis akut merupakan salah satu penyakit yang sering menyerang bayi dan anak. Penyebab utama rawat inap pada anak usia di bawah 5 tahun dengan gastroenteritis akut adalah dehidrasi. Penelitian dilakukan untuk mengetahui hubungan karakteristik pasien, derajat klinis dan suplementasi diare pada lama rawat inap diare akut pada anak usia di bawah 5 tahun. Studi dilakukan dengan desain observational analitik pada 102 anak-anak berusia antara 1 bulan sampai 5 tahun, yang menderita diare akut dengan atau tanpa dehidrasi yang dirawat di RSUD Pasar Rebo Jakarta pada bulan Oktober 2011 sampai bulan Maret 2012. Hasil menunjukkan kejadian diare lebih banyak pada pada bayi $<2$ tahun $(65,7 \%)$, anak laki-laki sebanyak 53 (52\%). Pada saat pemeriksaan awal, sebagian besar pasien berada pada derajat dehidrasi ringan-sedang yaitu sebanyak 89 orang $(87,3 \%)$. Lebih dari separuh, pasien dalam studi ini tidak diberikan terapi zink dan/atau probiotik yaitu sebanyak 53 orang (52\%). Rerata lama masa rawat pasien adalah 66,19 jam (SD=16,66 jam) atau 2,8 hari. Usia $(p=0,09)$, jenis kelamin $(p=0,165)$ dan derajat dehidrasi tidak mempunyai hubungan dengan lama perawatan, sedangkan berat badan $(p=0,913)$ dan tinggi badan $(p=0,014)$ mempunyai pengaruh terhadap lama perawatan. Pemberian suplementasi zink saja (mean $=56,68$ ) atau zink ( $m e a n=56,48)$ dengan probiotik memberikan masa rawat inap inap yang secara signifikan $(p=0,01)$ lebih pendek dibandingkan tanpa suplemen (mean=75,07). Tidak ada perbedaan signifikan $(p=1)$ lama rawat inap antara suplementasi zink saja atau dengan kombinasi probiotik. Derajat diare tidak mempunyai hubungan signifikan dengan lama perawatan. Dapat disimpulan bahwa suplementasi zink menurunkan lama rawat inap.
\end{abstract}

Kata Kunci: Gastroenteritis akut, lama perawatan, suplementasi zink

\begin{abstract}
Acute gastroenteritis is the most common disease on baby and children. Dehydration is the main reason for children under 5 with acute gastroenteritis required hospitalization. The research aim to explore the relation of patient characteristic, clinical stadium, diarrhea supplementation and the length of stay on children under 5 with acute diarrhea. This is analytic observational study on 102 children within the age range of 1 month-5 years, hospitalized with acute diarrhea, with or without dehydration, treated in Pasar Rebo District General Hospital on October 2011-March 2012. Result showed that more diarrhea cases happen to baby under $<2$ years $(65,7 \%)$, boy 53 cases (52\%). On early examination, $87,3 \%$ of the patients under mild to moderate dehydration (89 children). More than half of the patients were not given zinc or pro-biotic supplementation (53 children, 52\%). The average of length of stay is 66.19 hours (SD=16,66 hours) or 2,8 days. Age $(p=0,09)$, sex $(p=0,165)$ and dehydration stage has no correlation with length of stay, meanwhile weight $(p=0,913)$ and height $(p=0,014)$ has correlation with length of stay. Zink supplementation alone $($ mean=56,68) or zink with probiotic (mean $=56,48)$ significantly shorten the length of stay $(p=0,01)$ compared to without supplementation (mean=75,07). There is no significant difference on the length of stay of zink supplementation or probiotic combined ( $p=1)$. There is no significance correlation between lengths of stay of patient with dehydration stage caused by acute diarrhea on children under 5. Zink supplementation is the only determinants for length of stay.
\end{abstract}

Keywords: Acute gastroenteritis, length of stay, zink supplementation

Jurnal Kedokteran Brawijaya, Vol. 27, No. 4, Agustus 2013; Korespondensi: Endang Poerwati. Rumah Sakit Umum Daerah Pasar Rebo Jakarta, Jl. Raya Condet No.30, Jakarta TimurTel.(021)8400109,8401127Email:drendang_poer@yahoo.com 


\section{PENDAHULUAN}

Gastroenteritis akut merupakan salah satu penyakit paling umum pada bayi dan anak-anak. Angka rawat inap akibat gastroenteritis untuk anak-anak di bawah 5 tahun dilaporkan sebanyak 9 per-1000 pertahun di Amerika Serikat setiap tahun, sedangkan di Inggris sebanyak 12 per-1000 dan di Australia sebanyak 15 per-1000. Pada negara berkembang angka rawat inap akibat diare pada anak-anak sebesar 26 per-1000, misalnya di negara Cina (1).

Di seluruh dunia penyakit diare merupakan penyebab utama angka kesakitan dan kematian pada anak-anak, dengan 1,5 miliar kejadian dan diperkirakan setiap tahunnya angka kematian sebesar 1,5 sampai 2,5 juta di antara anak-anak berusia di bawah 5 tahun (2). Walaupun kenyataan kebanyakan perawatan di rumah sakit untuk penyakit diare sebenarnya dapat dihindari, khususnya setelah dimulai dengan pengobatan rehidrasi oral/oral rehydration therapy (ORT), penyakit diare masih merupakan alasan utama untuk kunjungan instansi gawat darurat dan rawat inap (3).

Gastroenteritis dengan dehidrasi merupakan penyebab utama morbiditas pada anak-anak. Di Amerika Serikat setiap tahun diperkirakan $>20$ juta kejadian diare pada anak-anak $<5$ tahun, dengan angka rawat jalan 1,5 juta, angka rawat inap 220000 dan jumlah kematian sebanyak 300 sampai 400 . Jumlah keseluruhan lama masa rawat di rumah sakit 925000 hari, dan menghabiskan dana sebesar 2 miliar dollar Amerika Serikat (4). Gastroenteritis akut merupakan salah satu alasan utama anak-anak dirawat di rumah sakit (5).

Salah satu kemajuan dibidang medis yang terpenting pada abad ke 20 adalah telah dikembangkannya cairan rehidrasi oral/Oral Rehydration Solution (ORS) untuk pengobatan penyakit diare. Cairan rehidrasi oral telah terbukti efektif dalam pencegahan dan pengobatan terhadap dehidrasi yang disebabkan penyakit diare. Penggunaan cairan rehidrasi oral ini telah direkomendasikan oleh World Health Organization (WHO) selama 2 dekade lalu. American Academy of Pediatrics (AAP) merekomendasikan rehidrasi cepat dalam waktu 4 sampai 6 jam dengan cairan rehidrasi glukosa-elektrolit oral yang diikuti dengan formula atau susu yang diencerkan (6).

Ada kecenderungan bahwa pemberi cairan intravena lebih sering digunakan dibanding cairan oral, walaupun pengunaan cairan rehidrasi oral itu lebih aman, lebih fisiologis, tidak nyeri, dan lebih murah dibanding penggunaan cairan intravena. Meskipun rekomendasi rehidrasi oral untuk mengatasi dehidrasi ringan dan sedang, sudah diajarkan tetapi pemakaian pengobatan ini masih dibawah 30\% dari kasus diare di Amerika Serikat (8).

Penilaian tingkat keparahan dehidrasi masih tergantung pada penemuan hasil pemeriksaan klinis. Publikasi WHO, AAP dan suatu tinjauan sistematik yang baru dipublikasikan setuju bahwa gabungan tanda-tanda, walaupun secara relatif kurang akurat, merupakan alat terbaik yang dapat digunakan oleh paramedis yang menjalankan praktek (9). Variasi dalam penerapan standar, termasuk didalamnya jenis rehidrasi akan mempengaruhi salah satu luaran pelayanan yaitu lama perawatan. Memanjangnya masa perawatan akan mempengaruhi risiko infeksi nosokomial dan biaya kesehatan. Tujuan penelitian ini untuk melihat hubungan karakteristik pasien, derajat dehidrasi, suplementasi pada kasus diare akut pada anak-anak usia di bawah 5 tahun dengan lama masa rawat di rumah sakit. Hasil penelitian diharapkan dapat memberikan dasar dalam mengembangkan standar manajemen perawatan diare akut pada anak dibawah 5 tahun.

\section{METODE}

Penelitian ini merupakan suatu penelitian observasional analitik, untuk menilai hubungan antara derajat dehidrasi akibat diare akut pada anak di bawah usia 5 tahun dengan lama masa rawat di rumah sakit. Penelitian dilakukan di RSUD Pasar Rebo Jakarta. Waktu penelitian dilaksanakan selama enam bulan mulai bulan Oktober 2011 sampai Maret 2012. Populasi target adalah anak dengan usia 1 bulan sampai usia 59 bulan yang menderita diare akut. Populasi terjangkau adalah populasi target yang datang berkunjung ke RSUD Pasar Rebo Jakarta selama bulan Oktober 2011 sampai bulan Maret 2012. Sampel adalah populasi terjangkau yang memenuhi kriteria inklusi yaitu Anak usia 1 bulan sampai usia 59 bulan dengan diagnosa gastroenteritis akut yang memerlukan rawat inap, tanpa disertai penyakit berat lainnya, yang berlangsung tidak lebih dari 7 hari. Pengolahan data dilakukan dengan menggunakan perangkat lunak SPSS versi 15 , dengan tingkat kemaknaan $p<0,05$ dan interval kepercayaan 95\%. Untuk melihat hubungan antar variabel digunakan uji ANOVA, uji regresi dan uji-t.

\section{HASIL}

Dari 118 anak dibawah usia 5 tahun yang menderita diare dirawat di rumah sakit, terdapat 16 anak yang dikeluarkan dari penelitian yang terdiri dari 5 anak dengan gizi buruk, 4 menderita diare persisten, 3 menderita penyakit HIV, 2 menderita ensefalitis, 1 menderita disentri amuba, dan 1 meninggal dunia, sehingga terdapat 102 pasien yang diikutkan dalam studi ini.

Pada studi ini (Tabel 1) didapati kejadian diare pada bayi $<2$ tahun sebanyak $67(65,7 \%)$ dan antara usia 2 sampai 5 tahun sebanyak 35 (34,3\%), dimana kejadian berdasarkan jenis kelamin terdapat anak laki-laki sebanyak 53 (52\%) sedangkan anak perempuan sebanyak 49 (48\%). Pada saat masuk rumah sakit rerata berat badan pasien adalah 10,36 $\mathrm{kg}(\mathrm{SD}=2,89 \mathrm{~kg})$. Setelah dilakukan rehidrasi rerata berat badan pasien meningkat menjadi $10,93 \mathrm{~kg}(\mathrm{SD}=2,89 \mathrm{~kg})$. Pasien memiliki tinggi badan rata-rata $82,5 \mathrm{~cm}$. Pada saat pemeriksaan awal, sebagian besar pasien berada pada derajat dehidrasi ringan-sedang yaitu sebanyak 89 orang $(87,3 \%)$. Lebih dari separuh, pasien dalam studi ini tidak diberikan terapi zink dan/atau probiotik yaitu sebanyak 53 orang (52\%). Rerata lama masa rawat pasien adalah 66,19 jam (SD=16,66 jam) atau 2,8 hari.

Tabel 1. Karakteristik pasien dan determinan lama rawat inap

\begin{tabular}{|c|c|c|c|}
\hline Karakteristik & $N=102$ & Rerata rawat inap & $p$ \\
\hline Jenis Kelamin, n (\%) & & & 0,165 (uji $t$ ) \\
\hline - Laki-laki & $53(52)$ & $68,40 \pm 17,09$ & \\
\hline - Perempuan & 49 (48) & $63,8 \pm 16,01$ & \\
\hline Usia, bulan, $\mathrm{n}(\%)$ & & & 0,092 (uji $t$ ) \\
\hline$-\quad<2$ tahun & $67(65,7)$ & $63,97 \pm 14,55$ & \\
\hline - $\quad 2$ tahun -5 tahun & $35(34,3)$ & $70.43 \pm 19.62$ & \\
\hline Berat Badan Masuk, kg, mean (SD) & $10,36(2,89)$ & & $0,013\left(R^{2}=0.061\right)$ \\
\hline Berat Badan Rehidrasi, kg, mean (SD) & $10,93(2,89)$ & & \\
\hline Tinggi Badan, cm, mean (SD) & $82,5(15,44)$ & & $0,014\left(R^{2}=0.059\right)$ \\
\hline Derajat Dehidrasi, n (\%) & & & 0,45 (ANOVA) \\
\hline - Tanpa Dehidrasi & 1 (1) & 76 & \\
\hline - $\quad$ Ringan - Sedang & $89(87,3)$ & $65,4( \pm 16,61)$ & \\
\hline - Berat & $12(11,7)$ & $71,17( \pm 17,35)$ & \\
\hline Jenis Terapi, $n(\%)$ & & & 0,001 (ANOVA) \\
\hline - Zink & $28(27,5)$ & $\begin{array}{l}56,68(95 \% \text { Cl 52,19 } \\
-61,17)\end{array}$ & \\
\hline - $\quad$ Zink dan probiotik & $21(206)$ & $56,4851,29-61,66$ & \\
\hline - Tidak diberi terapi & $53(52)$ & $75,0670,68-79,44$ & \\
\hline
\end{tabular}


Usia dan jenis kelamin tidak memberikan perbedaan dalam lama terapi. Berdasarkan uji regresi faktor status gizi yang ditunjukkan dengan berat badan dan tinggi badan menunjukkan pengaruh signifikan terhadap lama rawat inap namun dengan explaining variance yang kecil (6\%). Hal ini menunjukkan lebih banyak faktor lain yang menjelaskan perbedaan lama rawat inap selain berat badan dan tinggi badan.

Secara klinis perbedaan derajat dehidrasi ternyata tidak memberikan perbedaan lama rawat inap yang signifikan. Pada satu pasien tanpa dehidrasi justru mempunyai rawat inap terpanjang. Rawat inap pasien dengan dehidrasi berat lebih lama 6 jam dibandingkan dehidrasi ringansedang. Perbedaan ini disamping tidak signifikan secara statistik, secara praktis juga tidak bermakna karena kurang dari 1 hari.

Didapatkan hubungan yang bermakna antara lama masa rawat di rumah sakit dengan perbedaan jenis terapi. Uji post hoc menunjukkan perbedaan lama rawat inap bermakna antara kelompok yang diberi terapi zink dengan kelompok yang tidak diberi terapi zink dan probiotik $(p=0,0001)$. Perbedaan yang bermakna juga didapatkan pada kelompok yang diberi terapi zink dan probiotik dengan kelompok yang tidak diberi terapi $(p=0,0001)$. Antara kelompok yang diberi terapi zink dan probiotik tidak mempunyai perbedaan lama rawat inap bermakna dengan kelompok yang mendapat terapi zink saja $(p=1,000)$. Dapat disimpulkan pemberian terapi zink saja atau zink dan probiotik memberikan lama rawat inap yang lebih pendek ( 1 hari) dibandingkan tanpa pemberian terapi. Pemberian terapi zink atau kombinasi tidak memberikan perbedaan lama rawat inap.

\section{DISKUSI}

Karakteristik klinis yang berhubungan dengan derajat dehidrasi adalah: keadaan umum, urine output, masa pengisian kapiler, turgor kulit, fontanela, mata, membrana mukosa, air mata, frekuensi pernafasan, frekuensi denyut jantung, tekanan darah, dan spesifik gravitas urine (10). Gold standard untuk diagnosa dehidrasi adalah pengukuran kehilangan berat badan secara mendadak,

\section{DAFTAR PUSTAKA}

1. Fonseca BK, Holdgate A, and Craig JC. Enteral vs Intravenous Rehydration Therapy for Children with Gastroenteritis. Archives of Pediatrics \& Adolescent Medicine. 2004; 158(5): 482-490.

2. King CK, Glass R, Bresee JS, et al. Acute Diarrhea: Oral Rehydration and Continued Feeds-The Best Therapy; AAP Grand Rounds. Morbidity and Mortality Weekly Report Recommendations and Reports. 2004; 11(2): 13-24.

3. Tieder JS, Robertson A, and Garrison MM. Pediatrics Hospital Adherence to the Standard of Care for Acute Gastroenteritis. Pediatrics. 2009; 124(6): 1081-1087.

4. Ozuah PO, Avner JR, and Stein REK. Oral Rehydration Emergency Physicians and Practice Parameters. Pediatrics. 2002; 109(2): 259-261.

5. Goldman RD, Friedman JN, and Parkin PC. Validation of the Clinical Dehydration Scale for Children with Acute Gastroenteritis. Pediatrics. 2008; 122(3): 545549. yaitu selisih berat badan sebelum dan sesudah pemberian cairan. Secara klinis standar ini dapat didefiniskan sebagai kekurangan cairan yang ditentukan dari pertambahan berat badan setelah rehidrasi (11).

Peneliti Goldman RD et al, menilai derajat dehidrasi dengan menggunakan clinical dehydration scale (CDS) melaporkan ada hubungan yang positif antara derajat dehidrasi dengan lama masa rawat, yaitu semakin berat derajat dehidrasi maka semakin lama masa rawat di rumah sakit (5). Hasil studi ini tidak ada hubungan yang bermakna antara lama masa rawat di rumah sakit dengan perbedaan derajat dehidrasi akibat diare akut pada anak-anak usia di bawah 5 tahun. Diare dan malnutrisi sangat umum pada anak-anak di negara yang sedang berkembang, dan antara diare dengan malnutrisi mempunyai hubungan timbal balik, karena diare dapat menyebabkan malnutrisi, dan sebaliknya malnutrisi dapat memperberat dan memperpanjang kejadian diare. Hal ini juga ditunjang dengan fakta bahwa berat badan dan tinggi badan mempunyai pengaruh signifikan terhadap lama rawat inap, meskipun dengan explaining variance yang rendah.

Pada bulan Mei tahun 2004, WHO dan UNICEF merekomendasikan gabungan pemberian suplementasi zink bersama ORS dengan osmolaritas rendah yang dilanjutkan dengan feeding yang terbukti merupakan pendekatan pengobatan diare yang paling efektif. Dengan mengimplementasikan rekomendasi baru ini, telah diperkirakan hampir 90\% kematian akibat diare dapat dihindari. Pemberian zink bersamaan dengan ORS mengurangi durasi dan keparahan diare akut dibandingkan dengan pemberian ORS saja. Dalam studi ini penderita yang tidak diberikan terapi zink dan/atau probiotik sebesar 53 pasien (52\%). Pemberian zink saja atau dengan kombinasi probiotik memberikan perbedaan yang bermakna lama perawatan (lebih pendek satu hari) dibandingkan tanpa terapi. Studi ini juga menunjukkan bahwa pemberian tambahan probiotik tidak memberikan perbedaan lama rawat inap dengan hanya pemberian zink. Dapat disimpulkan bahwa lama rawat inap pada balita dengan diare akut tidak dipengaruhi oleh derajat klinis tetapi lebih dipengaruhi suplementasi zink serta status gizi pasien (berat dan tinggi badan).

6. Bezerra JA, Stathos TH, Duncan B, Gaines JA, and Udall JN Jr. Treatment of Infants with Acute Diarrhea: What's Recommended and What's Practiced. Pediatrics. 1992; 90: 1-4.

7. Duggan C, Lasche J, McCarty M, et al. Oral Rehydration Solution for Acute Diarrhea Prevents Subsequent Unscheduled Follow-Up Visit. Pediatrics. 1999; 104(3): 1-5.

8. Steiner MJ, DeWalt DA, and Byerley JS. Is this Child Dehydrated. The Journal of American Medical Association. 2004; 291(22): 2746-2754.

9. Shavit I, Brait R, Jordan CN, Galbraith R, and Jhonson D. A Novel Imaging Technique to Measure Capillary Refill Time; Improving Diagnostic Accuracy for Dehydration in Young Children with Gastroenteritis. Pediatrics. 2006; 118(6): 2402-2408.

10. Friedman JN, Goldman RD, Srivastava R, and Parkin PC. Development of a Clinical Dehydration Scale for Use in Children Between 1 and 36 Months of Age. The Journal of Pediatrics. 2004; 145(2): 201-207. 
11. Gorelick MH, Shaw KN, and Murphy KO. Validity and Reliability of Clinical Signs in the Diagnosis of Dehydration in Children. Pediatrics. 1997; 99(5): 16.

12. DeWitt TG. Acute Diarrhea in Children. Pediatrics in Review. 1989; 11(1); 6-13.

13. Moris SS, Cousens SN, Kirkwood BR, Arthur P, and Ross DA. Is Prevalence of Diarrhea a Better Predictor of Subsequent Mortality and Weight Gain than Diarrhea Incidence? American Journal of Epidemiology. 1996; 144(6): 582-588.

14. Fagundes-Neto $U$ and de Andrade JA. Acute Diarrhea and Malnutrition: Lethality Risk in Hospitalized Infant.
Journal of the American College of Nutrition. 1999; 18(4): 303-308.

15. Malek MA, Curns AT, Holman RC, et al. Diarrhea and Rotavirus-Assiciated Hospitalizations among Children Less than 5 Years of Age. United States, 1997 and 2000. Pediatrics. 2006; 117(6): 1887-1892.

16. Elliott EJ and Dalby-Layne RD. Acute Infectious Diarrhea and Dehydration in Children. Medical Journal of Australia. 2004; 181(10): 565-570.

17. Soenarto Y. Buku Ajar Gastroenterologi-Hepatologi. Jakarta: IDAI; 2010; Hal. 121-135. 